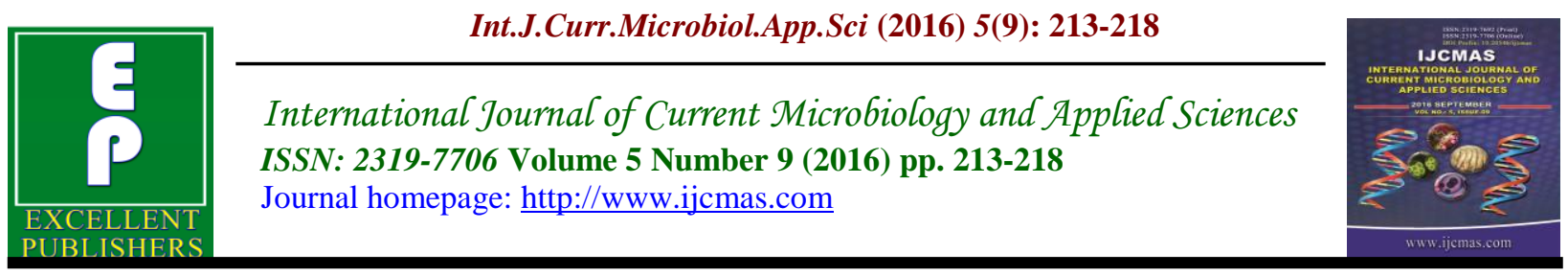

Original Research Article

http://dx.doi.org/10.20546/ijcmas.2016.509.024

\title{
Isolation Identification and its Drug Susceptibility Pattern in Orthopaedic Wound Infections
}

\author{
B. Chandrashekhara*, Vishwajith and S. Sangeetha \\ Department of Microbiology, Rajarajeswari Medical College and Hospital - 560 074, India \\ *Corresponding author: chandu_23scp@yahoo.co.in
}

Keywords

Orthopaedic

infection,

antibiotics, drug

resistance, MRSA,

Gram negative

bacilli.

Article Info

Accepted:

13 August 2016

Available Online:

10 September 2016

\section{A B S T R A C T}

Orthopaedic infections are associated with a high morbidity, often requires an aggressive antibiotic therapy. Bone infections remmains a serious therapeutic challenge and increasing resistance has complicated the management of infections. Delayed or ineffective treatment causes significant morbidity in terms of pain, loss of function and the need for further surgery and antibiotics. To study the aerobic bacteriological spectrum and antibiotic susceptibility pattern of isolates of orthopaedic wound infections. We performed a retrospective review of clinical and microbiological data sets using the access database of patients admitted in orthopedic ward for one year from august 2015 to july 2016. Out of 196 samples, $144(73.46 \%)$ yielded pure growth, $42(21.42 \%)$ mixed growth, 10(5.1\%) showed no growth. Out of 230 bacterial strains isolated 112(48.69\%) were Staphylococci and $118(51.3 \%)$ were Gram negative bacilli. Among the Staphylococcus spp, MRSA (50\%), MSSA (33.9\%), MSCONS (9\%) and MRCONS (7.1\%). Susceptibility pattern of MRSA isolates were $68 \%$ to cotrimaxozole, $43 \%$ to clindamycin, $29 \%$ to erythromycin, $18 \%$ to gentamycin and all MRSA strains were sensitive to Vancomycin and Linezolid. Among Gram negative bacilli, Pseudomonas (25.4\%), Escherichia coli(22\%), Enterobacter (22\%), Klebsiella (15.3\%), Citrobacter (8.4\%), Acinetobacter (3.3\%) and Proteus (3.3\%). Pseudomonas strains showed $100 \%$ sensitivity to imipenem, $87 \%$ to piperacillin-tazobactum, $73 \%$ to amikacin, $66 \%$ to cefotaxime, $47 \%$ to ciprofloxacin, $27 \%$ to gentamycin. Knowing the prevalence and the antibiotic susceptibility pattern of the isolates, helps us to guide the clinician to select the most appropriate antibiotics thereby preventing indiscriminate use of antibiotics.

\section{Introduction}

The problem of changes in pathogenic microbiological flora and the emergence of bacterial resistance has created major problems in the management of orthopaedic diseases and fractures. Due to the use of implants for open reduction and internal fixation, which are foreign bodies to the body, orthopaedic trauma surgery is at grave risk of microbiological contamination and infection (Alok, 2008).

The pathogenesis of infection in fractures, fixation devices is related to 
microorganisms, which grow in biofilm, and therefore its eradication is difficult (Trampuz et al., 2006). In human the most common route by which bacteria reach the bone is blood stream (Glover et al., 1982; Willis et al., 1996). However, traumatic modes as penetrating injury (Gale, 1991), fractures and intra-medullary nailing (Courtbrown et al., 1992), implants and postsurgical complications (Khan et al., 1997) have been identified. Intravenous drug users (Boll et al., 1990; Lobati et al., 2001) and the presence of foreign body (Park, 2005) also predispose to bone infection.

The various factors influence the nature and frequency of infection like low resistance of patients, contact with infectious persons, contaminated environmental sites and drug resistance of endemic organisms (Park, 2005). The source of an infecting organism may be present in patients body i.e. endogenous or exogenous in which organisms may be from another patient or a member of the hospital staff or from the inanimate environment of the hospital. The environmental sources like air, water, food, medication, equipment/instrumentation, soiled linen, hospital waste and contamination of wounds during the time of injury by dirt, soot, grease etc. play an important role in orthopaedic infections.

During the past few years, there has been remarkable improvement in the field of diagnosis of infection due to newer techniques, better health care systems, increasing awareness of patients; and invention of newer, more effective, and less toxic antimicrobials for combating osteoarticular infections. Orthopaedic wound infections are difficult to treat or eradicate completely in the absence of early diagnosis and prompt treatment or failure of antibiotic therapy due to development of drug resistance, these infections are still an important cause of high morbidity. Proper management requires accurate microbial isolation and appropriate antibiotic administration.

Keeping this in mind we decided to evaluate the data to know the aerobic bacterial etiological agents in orthopaedic wound infections and their antimicrobial susceptibility pattern. The analysed information can be utilized for starting empirical treatment.

\section{Materials and Methods}

We performed a retrospective review of clinical and microbiological data using the access database of samples received in our department from orthopaedic wound infection cases admitted in orthopaedic ward.

The following information were noted name, age, sex, case history, pre-operative antibiotics used, organism isolated and the antibiotic susceptibility.

\section{Results and Discussion}

Out of 196 cases studied, 148 (75.5\%) were males and $48(24.5 \%)$ were females. The cases were more in the age group of 31-40 years i.e.66 $(33.7 \%)$ and $36(18.4 \%)$ cases were of age group 41-50 years shown in Table 1

Wound infections were most common in fracture leg and foot accounting to $57.1 \%$ followed by fracture neck and shaft of femur $(24.5 \%)$.(Table 2)

Out of 196 samples, 144(73.46\%) yielded pure growth, 42(21.42\%) mixed growth, $10(5.1 \%)$ showed no growth.

Out of 230 bacterial strains isolated 112(48.69\%) were Staphylococci and $118(51.3 \%)$ were Gram negative bacilli. 
Among the Staphylococcus spp, Methicillin Resistant Staphylococcus aureus (MRSA) 50\%, Methicillin Sensitive Staphylococcus aureus (MSSA)33.9\%, Methicillin Sensitive Coagulase Negative Staphylococcus (MSCONS) 9\% and Methicillin Resistant Coagulase Negative Staphylococcus (MRCONS)7.1\%.

Methicillin resistant staphylococci were found be resistant to routinely used antibiotics compared to Methicillin Sensitive Staphylococci. All of them were found to be sensitive to Vancomycin and Linezolid (Table 3)
Among Gram negative bacilli, Pseudomonas 30(25.4\%), Escherichia coli 26(22\%), Enterobacter 26 (22\%), Klebsiella 18(15.3\%), Citrobacter 10(8.4\%), Acinetobacter 4 (3.3\%) and Proteus 4(3.3\%). (Table 4)

The data of antimicrobial susceptibility of gram negative bacilli showed reduced susceptibility to cefotaxime, gentamicin and ciprofloxacin. They showed better susceptibility to amikacin and piperacillintazobactum. Most effective antimicrobial agent was imipenem (Table 5)

Table.1 Showing age and sex distribution

\begin{tabular}{|c|c|c|c|}
\hline $\begin{array}{c}\text { Age group (in } \\
\text { years) }\end{array}$ & $\begin{array}{c}\text { Males } \\
\mathrm{No}(\%)\end{array}$ & $\begin{array}{c}\text { Females } \\
\mathrm{No}(\%)\end{array}$ & $\begin{array}{c}\text { Total } \\
\mathrm{No}(\%)\end{array}$ \\
\hline $0-10$ & $0(0)$ & $0(0)$ & $0(0)$ \\
\hline $11-20$ & $22(15)$ & $4(8.5)$ & $26(13.3)$ \\
\hline $21-30$ & $20(13.5)$ & $6(12.5)$ & $26(13.3)$ \\
\hline $31-40$ & $42(28.4)$ & $24(50)$ & $66(33.7)$ \\
\hline $41-50$ & $30(20.3)$ & $6(12.5)$ & $36(18.4)$ \\
\hline $51-60$ & $18(12.1)$ & $2(4)$ & $20(10.2)$ \\
\hline $61-70$ & $10(6.7)$ & $6(12.5)$ & $16(8.1)$ \\
\hline 71 and above & $6(4)$ & $0(0)$ & $6(3)$ \\
\hline Total $(\%)$ & $148(100)$ & $48(100)$ & $196(100)$ \\
\hline \multicolumn{4}{|r}{}
\end{tabular}

Table.2 Distribution of Wound Infection by Bone Fracture Site

\begin{tabular}{|l|c|c|}
\hline Bones affected & Number & Percentage \\
\hline \# Neck and shaft of Femur & 48 & 24.5 \\
\hline \# Leg and Foot & 112 & 57.1 \\
\hline \# Humerus & 16 & 8.2 \\
\hline \# Forearm and Hand & 8 & 4.1 \\
\hline Infected implant in situ & 12 & 6.1 \\
\hline Total & 196 & 100 \\
\hline
\end{tabular}

Table.3 Susceptibility pattern of MRSA, MSSA, MRCONS AND MSCONS

\begin{tabular}{|c|c|c|c|c|}
\hline Antibiotics & MRSA & MSSA & MRCONS & MS CONS \\
\hline Linezolid & $56(100 \%)$ & $38(100 \%)$ & $8(100 \%)$ & $10(100 \%)$ \\
\hline Vancomycin & $56(100 \%)$ & $38(100 \%)$ & $8(100 \%)$ & $10(100 \%)$ \\
\hline Cotrimaxozole & $38(68 \%)$ & $20(53 \%)$ & $4(50 \%)$ & $6(60 \%)$ \\
\hline Clindamycin & $24(43 \%)$ & $28(74 \%)$ & $6(75 \%)$ & $10(100 \%)$ \\
\hline Erythromycin & $16(29 \%)$ & $16(42 \%)$ & $4(50 \%)$ & $6(60 \%)$ \\
\hline Gentamycin & $10(18 \%)$ & $16(42 \%)$ & $2(25 \%)$ & $8(80 \%)$ \\
\hline
\end{tabular}


Table.4 Distribution of various Gram negative bacilli

\begin{tabular}{|c|c|c|}
\hline ORGANISMS & Number & Percentage \\
\hline Pseudomonas & 30 & 25.4 \\
\hline Escherichia coli & 26 & 22 \\
\hline Enterobacter & 26 & 22 \\
\hline Klebsiella & 18 & 15.3 \\
\hline Citrobacter & 10 & 8.4 \\
\hline Acinetobacter & 4 & 3.3 \\
\hline Proteus & 4 & 3.3 \\
\hline TOTAL & 118 & 100 \\
\hline
\end{tabular}

Table.5 Susceptibility pattern of Gram negative bacterial isolates

\begin{tabular}{|c|c|c|c|c|c|c|c|}
\hline Antibiotics & Pseudomonas & Escherichia coli & Enterobacter & Klebsiella & Citrobacter & Acinetobacter & Proteus \\
\hline Cefotaxime & $20(66 \%)$ & $8(31 \%)$ & $10(38 \%)$ & $10(56 \%)$ & $4(40 \%)$ & $2(50 \%)$ & $2(50 \%)$ \\
\hline $\begin{array}{l}\text { Piperacillin- } \\
\text { Tazobactum }\end{array}$ & $26(87 \%)$ & $14(54 \%)$ & $18(69 \%)$ & $16(89 \%)$ & $8(80 \%)$ & $4(100 \%)$ & $4(100 \%)$ \\
\hline Gentamycin & $8(27 \%)$ & $16(62 \%)$ & $8(31 \%)$ & $10(56 \%)$ & $8(80 \%)$ & $4(100 \%)$ & $2(50 \%)$ \\
\hline Amikacin & $22(73 \%)$ & $20(77 \%)$ & $12(46 \%)$ & $12(67 \%)$ & $8(80 \%)$ & $4(100 \%)$ & $4(100 \%)$ \\
\hline Ciprofloxacin & $14(47 \%)$ & $10(38 \%)$ & $16(62 \%)$ & $8(44 \%)$ & $6(60 \%)$ & $4(100 \%)$ & $4(100 \%)$ \\
\hline Imipenem & $30(100 \%)$ & $22(85 \%)$ & $22(85 \%)$ & $16(89 \%)$ & $10(100 \%)$ & $4(100 \%)$ & $4(100 \%)$ \\
\hline
\end{tabular}

Analyzing our data base, we could find 196 cases of orthopaedic wound infection in which $75 \%$ were males and $25 \%$ were females. Most of the patients were between the age group of 31-40 years in both the genders $50 \%$ of the females belong to this age group. This is the age at which they are employed and they travel with stress to their work place in the two wheelers so vulnerable for road traffic accidents which leads to orthopaedic problems and admitted in the hospital predispose them to infection. This correlates with the study conducted by Faria Malik, Zuluana AF et al., (1999, 2006).

Wound infections were most common in lower limbs (81.6\%) followed by upper limbs $(12.3 \%)$ in the present study. Probably lower limbs are more prone for injuries and contamination by soil and maintenance of hygiene is difficult all these predisposes for infections.

A study conducted by Samuel et al., also showed the lower limbs were affected in
$71.5 \%$ of cases, the upper limbs in $22.1 \%$, and the head and neck in $3.5 \%$ (Samuel, 2008).

A study conducted by Samuel B A et al., in 2008 showed Staphylococcus aureus (37.6\%) as the most common isolate followed by Coliforms (11.2\%) in chronic osteomyelitis. This correlates with our study wherein Staphylococcus aureus (41\%) and Pseudomonas species (13\%) were the most common organisms associated with wound infections which is in line with other studies and standard patterns. A Retrospective French Multicenter study by Jacques Merrer, Alain -Jacob, Philippe Montravers showed MRSA (32\%) as the most common isolate, followed by Pseudomonas aeruginosa $(23 \%)$ in orthopaedic infections (Jacques Merrer et al., 2007) but the study conducted by Sule ,Thanni, Olusanya showed Pseudomonas aeruginosa(26\%) as the most common isolate followed by Staphylococcus aureus(17\%) and Klebsiella $(17 \%)$ in orthopaedic wound infections (Sule et al., 2002). 
The pathogens isolated showed marked resistance to the routinely used antimicrobial agents. Gram positive isolates $60 \%$ showed sensitivity to Cotrimoxazole and Clindamycin. All the isolates were susceptible to Vancomycin and Linezolid. Among the gram negative isolates maximum susceptibility was observed towards Imipenem followed by PiperacillinTazobactum, Amikacin and Gentamycin.

In conclusion, orthopaedic wound infections are usually the sequel of trauma. Our study has helped us to know about the organisms responsible for infection and its susceptibility pattern. Every hospital will have diverse microbial flora which are responsible and exhibit different susceptibility pattern. Isolation of causative organism and performance of antibiotic sensitivity studies are critical in the selection of antimicrobial agents. This type of study helps to assess etiological agents in orthopedic wound infections and comparison of effects of different antibiotics on microorganisms in vitro in order to utilize its results for quick and appropriate antibiotic selection before the availability of culture and antibiogram results. Thus it will help in selection of correct treatment and prevents development of drug resistance by indiscriminate use of antibiotics.

\section{References}

Alok. C. 2008. Agrawal, Shuddhatma Jain,"Pathogenic bacteria in an orthopaedic hospital in India", $J$. Infect. Develop. Countries, 2(2): 120123.

Boll, K.L., Jurik, A.G. 1990. "Sternal osteomyelitis in drug addicts", J. Bone Joint Surg., 72B: 328-9.

Court-brown, C.M., Keating, J.F., McQueen, M.M. 1992. "Infection after Intra-medullary nailing of the tibia", J. Bone Joint Surgery, 74B: 770-4.

Faria Malik. 1999. "Bacterial aetiology of osteomyelitis cases at four hospitals of Lahore", J. Ayub. Med. Coll. Abbottabad, 15: 224-7.

Gale, W., Scott, R. 1991. "Puncture wound of the foot? Persistent pain? Think of Pseudomonas aeroginosa osteomyelitis", Injury: $\mathrm{Br} . \mathrm{J} . \mathrm{Acci}$. Surg., 22(5): 427-8.

Glover, S.C., Padfield, C., McKendrick, M.W., Geddes, A.M., Dwyer, N.J.P. 1982. "Acute osteomyelitis in a district general hospital", Lancet, 1: 609-11.

Jacques Merrer, Emmanuelle Girou. 2007. "Surgical Site Infection After Surgery to Repair Femoral Neck Fracture: A French Multicenter Retrospective Study", Infect. Control and Hosp. Epidemiol., Vol. 28, No. 10.

Kak, V., Chanderasekar, P.H. 2002. "Bone and Joint infections in injection drug users", Infect. Dis. Clin. North Am., 16(3): 681-95.

Khan, G., Hussain, A., Rehman, M. 1997. "Infection of the sternum and costal cartilages following median sternotomy: Report of 4 cases", JPMI, 11(2): 224-9.

Lobati, F., Herndon, B., Bamberger, D. 2001. "Osteomyelitis: aetiology, diagnosis, treatment and outcome in a public versus a private institution", Infect., 29(6): 333-6.

Park, K. 2005. Infectious disease epidemiology, Text book of preventive and social medicine, 18th edition M.S. Banarsidas Bhanot publishers 85 .

Samuel, B., Agaja. 2008. "Chronic osteomyelitis in Ilorin, Nigeria", VOL 46, NO. 4, SAJS.

Sule, A.M., Thanni, Sule Odu, O.A. 2002. "Bacterial Pathogens Associated With Infected Wounds In Ogun State 
University Teaching Hospital, Sagamu, Nigeria", African J. Clin. Experimental Microbiol., Vol 3, No 1.

Trampuz, A., Zimmerli, W. 2006. "Diagnosis and treatment of infections associated with fracture fixation devices". Injury, 37 (suppl 2): S59-66.
Willis, R.B., Rozencwaig, R. 1996. "Pediatric osteomyelitis masquerading as skeletal neoplasia", Orthop. Clin. North Am., 27(3): 625-34.

Zuluaga, A.F., Galvis, W., Vesga, O. et al., 2006. "Etiologic diagnosis of chronicosteomyelitis", Arch. Intern. Med., 166: 95-100.

\section{How to cite this article:}

Chandrashekhara B., Vishwajith and Sangeetha S. 2016. Isolation Identification and its Drug Susceptibility Pattern in Orthopaedic Wound Infections. Int.J.Curr.Microbiol.App.Sci. 5(9): 213-218. doi: http://dx.doi.org/10.20546/ijcmas.2016.509.024 